\title{
Socialization Helps the Treatment of Depression in Modern Life
}

\author{
Sefa Bulut \\ Counseling Psychology and Guidance Department, Ibn Haldun University, Istanbul, Turkey \\ Email: sefabulut22@gmail.com
}

How to cite this paper: Bulut, S. (2019). Socialization Helps the Treatment of Depression in Modern Life. Open Journal of Depression, 8, 41-47.

https://doi.org/10.4236/ojd.2019.82005

Received: November 9, 2018

Accepted: March 19, 2019

Published: March 22, 2019

Copyright $\odot 2019$ by author(s) and Scientific Research Publishing Inc. This work is licensed under the Creative Commons Attribution International License (CC BY 4.0).

http://creativecommons.org/licenses/by/4.0/

\section{(c) (i) Open Access}

\begin{abstract}
Today modern people suffer from mental illnesses and depression is one of the most commonly diagnosed disorders among children and adults. The treatment of this disorder is long, expensive and sometimes there are no mental health professionals or medical opportunities to treat it. Therefore, we should understand the etiology of this problem and seek alternative methods for healing. This paper deals with non-traditional approach for the treatment of this mental health problem. Researchers found that one of the fundamental reasons for the depression is isolation, loneliness and lack of social support. If people can get some degree of social and emotional support, they will get through the difficult times easily and smoothly. Thus, we should provide natural settings for ourselves and our children to exercise their social skills and learn how to socialize.
\end{abstract}

\section{Keywords}

Depression and Social Support, Socialization, Learning, Non-Traditional Approach

\section{Introduction}

Medical field is as old as human history and physical health is one of the most important concerns of people as it is today. The $19^{\text {th }}$ century enlightened the people as they gained awareness about their consciousness and spirit and then with the effect of positivism, psychology came into existence and all other social sciences started utilizing positive methods as a tool for investigation and experimentations.

During $19^{\text {th }}$ Century, Freud and many of his followers emerged with fame in the field of psychology and this field became an important discipline for academicians and common people (Toffler, 1971: p. 159). Especially after 1960's 
common people seek to find a meaning in their lives because they were tired of capitalism and its demands as well as postindustrial problems. When people started to live in big cities, they got quality education and it brought to them mobility and loneliness. They enjoyed it for a couple of decades and after that they felt lonely, isolated and alienated from society and themselves. Then the search started for a better and meaningful life. However, it was too late because society demanded more and more individualized and capitalized individuals. Capitalism encouraged more commercialism and people felt they would be happier as they consumed more and they tried it for a while but the results showed that it was not true.

People had to work harder and pay for everything, buy everything and every service that previously family members or friends provided for them. Then commercialism and consumption became a trend. People spend more and more (Riesman, Glazer, \& Denney, 1954). They buy more than they actually need in their day to day lives. It became a way of personal hobby and fulfillment but in order to do that they had to work harder. Migration to big cities, increasing divorces rates, high mobility, longer work hours, lack of job security, single parenthood, school violence and such other critical social issues became very widespread.

Today in our society, there are people who do not have any casual friend and acquaintance because there are no social places or opportunities for people to socialize. At work, we used e-mails and WhatsApp to communicate with co-workers. We do not bother to say Good Morning to our neighbors in elevators; we do not invite friends at home spontaneously. Instead, we have organized days such as Christmas parties at work, best mother of the year, best worker of the year, or celebrate friend's birthday at work. Those are good activities but those are planned and organized previously and intentionally. The same thing is true for our kids as well. People and children do not have access to socialize freely and naturally. Organized activities do not provide humanly communication and interactions. Today societies are missing real and natural face to face human conversations. Either we do not have opportunities or we do not bother to socialize with other.

It is interesting that this year in England new ministry has been established for "Lonely" people and it can be found very meaningful. In today's society we try to teach children how to play at school or play in yard, how to thank people, how to say please, how to take turn, how to share, how to make friend, how to greet people. In fact, those are very basic and elementary skills that they need to learn in play ground or in street by themselves. Nevertheless, how pity, we send children to school counselor to learn these social skills. Children are lonely and get depressed because they do not have friends. They do not know how to develop friendships. They have social anxiety and social phobia because they are missing natural settings to learn those abilities. How pity!

How pity is for children coming from upper social classes as children from disadvantaged families have more opportunities for human conversations then 
kids from wealthy family. What it means is that besides physical and psychological health there is also "social health". Psychology books says that humans are bio-psycho-social being but by now we missed the social part. We have to discover and remember our social side of life.

\section{Social Health}

"Social Health" is also one of the important aspects our health. DSM-V suggests $\mathrm{V}, \mathrm{Z}$, or T codes for conditions that may asses client's social functioning. Similarly, psychosocial stressors are placed in V codes in ICD-9, and Z codes in ICD-10. This information can be used to provide information about patient's care. V-codes are usually used to show conditions and problems that affect the diagnosis process of the illness, prognosis, and treatment of the disorder. If these conditions are part of the treatment or explains the need for treatment or evaluation, then it could be used along with the mental disorder codes. These expanded codes can also be used in the patient's record to provide information about circumstances that may influence on their treatment. V/Z codes include acculturation difficulties, discrimination or persecution that the client may face and religious or spiritual problems they may experience. In previously used, GAF (Global Assessment of Functioning Scale, in Axis V, in DSM IV-TR is replaced by WHO-DAS (World Health Organization Disability Schedule, 2002). Now, in DSM V, it is optional to use WHO-DAS to asses client's psychosocial, occupational and relational problems and functioning. World Health Organization Disability Assessment Schedule version 2.0 (WHO-DAS) was developed to assess a client's ability to perform activities in the following six area of functionalities; those are understanding and communicating, getting around, self-care, getting along with people, daily life activities (house, work, school); and participation in society. Even in DSM-IV classification (An official classification of psychological disorder by American Psychiatric Association (2000), Diagnostic and Statistical Manual of Mental Disorder-IV-TR) there is an evaluation section of social health. All these classifications show how important is our social health and how it can affect our day to day life.

Mental health counselor tries to define the people's social functioning as they asses their available support networks and their relationships at work and their social skills. For the treatment of some psychological disorders people seek medical and psychological help but with lack of social dimension. Social aspects of health are important and integrated in treatment as well as educational systems. For example, depression as such, it is one of the most commonly diagnosed mental health problems among children, adolescents, adults and elderly population (Nolen-Hoeksema, 2001: p. 252). Therefore, depression is the one of the most severe illness of all kind. In the U.S.A. the prevalence of depression reached $9.5 \%$ of the population aged 18 or older demonstrate depressive symptoms. At least many people experience depression in their lifetime. Many depressed people often find hard to participate in social activities because of lack of 
energy or social interest (Evangelos \& Dimitrios, 2017). Psychologists mostly offer group therapies and activities as part of treatment because groups have tremendous effects on individuals well-being and happiness. Participant's feels understood, sees that others also experience similar problems, provides sense of belongingness, real human contacts, communications and humanly touch. Those are extremely powerful tools for human life. However, it is imperative to find ways to provide opportunities for socialization people spontaneously and regularly. Social groups have their own dynamics that members feel powerful and accepted which is good for social health.

Social health is important also because that would function as preventive factors for psychological health. Psychologists, counselors, social workers and teachers should encourage "human interactions in real settings". Researches and experiences show that organized and planed activities do not really serve its purpose. Such as organized birthday parties, Christmas parties, mother of the year and worker of the year type of celebration parties are not as effective as the natural encounters or a small talk between acquaintances. On the other hand, the modern life that we lead does not allow us to have natural and warm relations with people around us. Thus, it is important to take advantage of every opportunity that comes to us in order to meet, interact and converse with people.

It should not be difficult to invite a coworker for a coffee, it should not be burden to host a family member one or two day, it should not be difficult to cook for a neighbor. We are all missing our real humanness. We live in a cyber-age, we do everything via internet for example banking online, shopping online, etc. Even we do not see real people to have a short conversation or a small talk. Loneliness and isolation bring a tremendous stress, not feeling well, ostracized and feel different (Cleve, 1989: p. 181). Many depressed people feel lonely and they are very sensitive to rejection by others. Instead, they have to learn how to cultivate and maintain friendships. Maybe it is time to talk about "Social Health", how many hours now we spend with our friends, when was the last time we had guest at home, when was the last time we cooked for a friend. When was the last time we said "hello" to a stranger or have genuine interest someone whom we see in need of help? There have been many studies conducted about the effects of social activities and depression. In fact, there has been numerous researches involving children, preadolescents, adolescents, young adults and elderly population from different part of the world. To exemplify some, Lee and Kim (2014) investigated the effect of formal and informal activities in Korean elderly and looked at its effects on their depression level. They found that informal social activities; such as, often phone contact and exchanging letters with their adult children lowered the risk of depression. Especially, face-to-face contact with their children and friends has very positive effect on their well-being. On the other hand, formal activities for example religious activities, volunteering in somewhere, participating in community or family councils, engagement in social and political activities were not associated with man and women's depression. They concluded that informal social activities especially with close family 
members has great impact on elder population than the pre-set up social activities. In a similar Korean study with elderly participants Min, Ailshire, and Crimmins (2016) found that involving in social gatherings with friends and neighbors has a decreasing effect on depression and the type of engagement may have different effect. In a study with Brazilian elderly participants Alexandre, Cordeiro, and Ramos (2009) reported marital status, income and leisure activities as factors affecting the quality of life and depression of the people.

In another Brazilian study with elderly people, Ferreira and Barham (2018) reported that involving the elderly people in fun and pleasant activities plays an imperative role in intervention, prevention and treatment of depression. The more people engage in pleasant activities the more they feel better. World Health Organization (2002) proposed to all individuals stay active in their entire lifetime. This means remaining active in physically, socially and mentally. This would suggest the elderly population to involve in social, economic, cultural, spiritual and civic events. In the same vein, González-Herero and García-Martín (2012)'s study with elder Spanish women population, social activities, self-esteem and optimism was found to be significantly correlated with elder people life satisfaction and positive affect. In another Spanish study, Hombrados-Mendieta, Gomez-Jacinto, Dominguez-Fuentes and Patricia Garcia-Leiva (2013) compared the immigrant and native people in terms of sense of community and life satisfaction. Their results revealed that people with high sense of community has greater life satisfaction and sense of community served as a buffering effect on immigrant people adoption and coping process in new country.

In a study with Spanish university students Poch, Vilar, Caparros, Juan, Cornella, and Perez (2004) found that $13.9 \%$ of the students experience some degree of hopelessness; they are dissatisfied with university life and spend less time in extracurricular educational activities. They reported a relationship between depression, suicidal ideation and hopelessness. They suggested developing some intervention program to influence their mood and work on their adoption programs, which consequently improve their academic achievement as well. Dumont and Provost (1999) examined the internal and external factors in developing depressive symptoms and daily stress. Their results show that well-adjusted adolescent and resilient adolescents had higher self-esteem than the vulnerable adolescents did. Consequently, self-esteem has protecting effect on depression by receiving more social support and social activities. Similarly, Holffreter, Reisig and Turanovic (2015) studied elderly people's social participation in USA. They argue that depressed older adults tend to not to participate social activities. However, high quality family ties can provide supportive coping resources that buffer the effects of depression.

\section{Conclusion}

In sum, we can conclude that humanity has experienced such a long history and during this time duration humans evolved not only physically and psychologically but also socially. During these transformations it seemed there was the 
transitional stress and it had its own impact on human as a whole. However, life has not been as stressful as the modern people's life with huge technological invasion of his life. Loneliness, isolation and alienation have become a very widespread problem and so as the depression. Depression reached epidemic proportion for children, teenagers and adults. It appears that our modern world does not offer very satisfactory social activities and pleasant events. Then, it depends on the individuals' awareness and understanding of their life and makes their life more meaningful. Obviously, for this, they need real, caring and face-to-face interactions with their close friends and family members. They would be able to first initiate, invite or talk with the people around them. They need to appreciate everybody's humanness and give, take and share meaningful interactions.

\section{Conflicts of Interest}

The author declares no conflicts of interest regarding the publication of this paper.

\section{References}

Alexandre, T. S., Cordeiro, R. C., \& Ramos, L. R. (2009). Factors Associated to Quality of Life in Active Elderly. Revisit Saudi Publican, 43, 613-621. https://doi.org/10.1590/S0034-89102009005000030

American Psychiatric Association (2000). Diagnostic and Statistical Manual of Mental Disorders- $I V-T R$. Washington, $D C$.

Cleve, J. (1989). Out of the Blues: Strategies That Work to Get You through the Down Times. Comp Care Publishers.

Dumont, M., \& Provost, M. A. (1999). Resilience in Adolescents: Protective Role of Social Support, Coping Strategies, Self-Esteem, and Social Activities on Experience of Stress and Depression. Journal of Youth and Adolescence, 28, 343-363. https://doi.org/10.1023/A:1021637011732

Evangelos, S., \& Dimitrios, M. (2017). Social Participation of Depressed Individuals as an Optimization Problem. 2017 International Conference on Computational Science and Computational Intelligence, 1666-1671.

Ferreira, H. G., \& Barham, E. J. (2018). Relationship between Pleasant Event, Depression, Functionality and Socio-Demographic Variables in the Elderly. Paidéia, 28, 1-9. https://doi.org/10.1590/1982-4327e2815

González-Herero, V., \& García-Martín, M. A. (2012). Personality, Activities, and Well-Being: A Study Based on Women in Late Adulthood. Journal of Women \& Aging, 24, 152-168. https://doi.org/10.1080/08952841.2012.639662

Holffreter, K., Reisig, M. D., \& Turanovic, J. J. (2015). Depression and Infrequent Participation in Social Activities among Older Adults: The Moderating Role of High-Quality Familial Ties. Ageing \& Mental Health, 21, 379-388. https://doi.org/10.1080/13607863.2015.1099036

Hombrados-Mendieta, I. M., Gomez-Jacinto, L., Dominguez-Fuentes, J. M., \& Patricia Garcia-Leiva, P. (2013). Sense of Community and Satisfaction with Life among Immigrants and the Native Population. Journal of Community Psychology Journal of Community Psychology, 41, 601-614. https://doi.org/10.1002/jcop.21559

Lee, S. H., \& Kim, Y. B. (2014). Which Type of Social Activities Decrease Depression in the Elderly? An Analysis of a Population-Based Study in South Korea. Iranian Journal of Public Health, 43, 903-912. 
Min, J., Ailshire, J., \& Crimmins, E. M. (2016). Social Engagement and Depressive Symptoms: Do Baseline Depression Status and Type of Social Activities Make a Difference? Age and Ageing, 45, 838-843. https://doi.org/10.1093/ageing/afw125

Nolen-Hoeksema, S. (2001). Abnormal Psychology (Second Ed.) Pennsylvania Plaza New York City: McGraw-Hill Companies, Inc.

Poch, F. V., Villar, E., Caparros, B., Juan, J., Cornella, M., \& Perez, I. (2004). Feelings of Hopelessness in a Spanish University Population. Descriptive Analysis and Its Relationship to Adapting to University, Depressive Symptomatology and Suicidal Ideation. Social Psychiatry and Psychiatric Epidemiology, 39, 326-334.

Riesman, D., Glazer, N., \& Denney, R. (1954). The Lonely Crowd: A Study of the Changing American Character. Doubleday Anchor Books. Garden City, NY: Doubleday \& Company, Inc.

Toffler, A. (1971). Future Shock. Bantham Books. NY: A National General Company.

World Health Organization (WHO) (2002). Noncommunicable Diseases and Mental Health Cluster. Noncommunicable Disease Prevention and Health Promotion Department. Aging and Life Course. Active Aging: A Policy Framework. Geneva: WHO/NMH/NPH/02.8. 